\title{
Study on the Modes of Thermal Decomposition of Several Azo-Type Initiators
}

\author{
Kenji Yoshino, Yasukazu Ohkatsu, and Teiji Tsuruta \\ Department of Synthetic Chemistry, Faculty of Engineering, \\ University of Tokyo, 3-1, Hongo 7-chome, Bunkyo-ku, \\ Tokyo 113, Japan.
}

(Received November 30, 1976)

\begin{abstract}
Modes of thermal decomposition reactions of several azo-type initiators were studied in the presence or absence of a transition-metal complex. Some metal complexes examined cause dramatic influence upon the relative ratio of decomposition products. Particularly, a cobalt complex prevents the coupling reaction of radicals formed from azo compounds, with increased formation of noncoupling products being observed. Futhermore no difference was observed in the mole ratios of an unsymmetrical coupling product to the sum of symmetrical products in the decomposition of an unsymmetrical azo compound with or without a complex, $\mathrm{Co}(\mathrm{II})(\mathrm{sal})_{2}((\mathrm{R})-\mathrm{CHXDA})$. This phenomenon was satisfactorily explained by assuming that primary radicals immediately formed interact with the metal complex and are stabilized prior to subsequent reactions.

KEY WORDS Radical Decomposition / Azo Compound / Cage /

Organometallic Complex /
\end{abstract}

Up to the present, a great many papers have been presented on the decomposition reactions of azo-type initiators. Few papers, however, have dealt with other than the kinetics on the rate of decomposition of the azo-type compounds. The present study is concerned with the mode of decomposition reactions of several azo compounds. In vinyl polymerizations, it is important to have knowledge on decomposition products of initiators, because some of the products may cause potential influence on both the rate of polymerization and the properties of resulting polymers. The present paper also reports the effect of some transition-metal complexes on the mode of decomposition reactions of azo-type initiators.

\section{EXPERIMENTAL}

Syntheses of Azo Compounds

2,2' -Dimethyl-2,2' -azodipropionitrile

(I) was<smiles>CC(C)(C#N)N=NC(C)(C)C#N</smiles>

used after conventional purification of commercial reagent. $\mathrm{mp} 104-105^{\circ} \mathrm{C}$ (lit. $103-105^{\circ} \mathrm{C}$ ). ${ }^{1}$<smiles>CCC(C)(C#N)N=NC(C)(C#N)CC</smiles>

2,2' -Dimethyl-2, $2^{\prime}$-azodibutyronitrile (II) was prepared using a conventional method. ${ }^{1}$ The product was recrystallized three times from $90-\%$ ethanol. The yield, $36.4 \%$ to ethyl methyl ketone; $\mathrm{mp} 51-51.7^{\circ} \mathrm{C}$ (lit. $49-51^{\circ} \mathrm{C}$ ). ${ }^{1}$<smiles>CC(C)C(C)(C#N)N=NC(C)(C#N)C(C)C</smiles>

$2,2^{\prime}, 3,3^{\prime}$-Tetramethyl-2, $2^{\prime}$-azodibutyronitrile was prepared in the same procedure as in the case of $2,2^{\prime}$-dimethyl-2, $2^{\prime}$-azodibutyronitrile (II) except for the use of isopropyl methyl ketone in 
place of ethyl methyl ketone. ${ }^{1}$ The yield (after three-time recrystallization), $15.1 \% ; \mathrm{mp} 68.5-$ $72^{\circ} \mathrm{C}$ (lit. $68.5-70^{\circ} \mathrm{C}$ ).<smiles>CC(C)(C)C(C)(C)N=NC(C)(C#N)C(C)(C)C</smiles>

$2,2^{\prime}, 3,3,3^{\prime}, 3^{\prime}$-Hexamethyl-2, $2^{\prime}$-azodibutyronitrile (IV) was prepared via pinacolone ketazine. ${ }^{2}$ The azine was prepared first and then treated with liquid hydrogen cyanide. Yield (after three-time recrystallization), 17.7\%; mp 114$116.5^{\circ} \mathrm{C}$ (lit. $112.5-114^{\circ} \mathrm{C}$ ). ${ }^{2}$<smiles>CCC(C)(C#N)N=NC(C)(C#N)C(C)C</smiles>

2,2',3-Trimethyl-2,2'-azodibutyronitrile (V) was prepared as follwing. A mixture of $44 \mathrm{~g}$ of isopropyl methyl ketone, $202 \mathrm{~g}$ of $100-\%$ hydrazine hydrate and $100 \mathrm{ml}$ of ethanol was refluxed for two days, followed by removal of the ethanol. The oily liquid layer was then separated from the excess hydrazine hydrate layer, and washed with water three times. A mixture of $5.46 \mathrm{~g}$ of the oily liquid and $4.3 \mathrm{~g}$ of ethyl methyl ketone was refluxed for ten hours. The reaction mixture was then dried over anhydrous calcium chloride, and $20 \mathrm{ml}$ of liquid hydrogen cyanide were added. The subsequent process was similar to those for the azo compound (IV). The crude product was recrystallized twice by adding water to an ethanol solution of the product. Yield, $3.0 \mathrm{~g}$ (26.7\%); mp $41-42^{\circ} \mathrm{C}$.

Preparation of Metal Complexes. Metal porphyrins, such as cobalt(II)tetraphenylporphyrin (Co(II)TPP), nickel(II)tetraphenylporphyrin(Ni (II)TPP), manganese(II)tetraphenylporphyrin(Mn (II)TPP), copper(II)tetraphenylporphyrin( $\mathrm{Cu}(\mathrm{II})$ TPP) were prepared as follows: Tetraphenylporphyrin $\left(\mathrm{H}_{2}\right.$ TPP) was prepared according to the method by Falk. ${ }^{3}$ Co(II)TPP was prepared according to the method by Rothemund and Menotti. ${ }^{4}$ Mn(II)TPP, Ni(II)TPP and $\mathrm{Cu}(\mathrm{II}) \mathrm{TPP}$ were prepared using manganese(II)acetate,
nickel(II)acetate, and copper(II)acetate, respectively, in place of cobalt(II)acetate.

$N, N^{\prime}$-bis(salicylaldehyde)-1(R), 2(R)-1,2-transcyclohexanediiminato cobalt(II) $\left[\mathrm{Co}(\mathrm{II})(\mathrm{sal})_{2}((\mathbf{R})\right.$ CHXDA)] was prepared according to the method by Aoi, et al. ${ }^{5}$

Solvent. Benzene was purified according to general method.

Decomposition of Azo Compounds. A solution of an azo compound with or without a metal complex in benzene was charged into an ampoule and degassed twice by a freeze-thaw method to remove oxygen, and the ampoule was sealed in vacuo. After placing the ampoule in an oil bath maintained at constant temperature, until the azo compound decomposed completely, the content of the ampoule was analyzed.

Analysis of Decomposition Products. The decomposition products were separated into volatile products and residue by a trap-to-trap method in vacuo. The volatile products were analyzed by means of GLC-MS, NMR, and IR. The residue, recrystallized from ethanol, was analyzed as coupling products by similar techniques. Results of characterization of the products are summarized in Table I.

Quantitative analyses of decomposition products were carried out mainly by GLC techniques using a column packed with silicone DC connected to silicone GESE. The column temperature was $60^{\circ} \mathrm{C}$ for the noncoupling products, and $160^{\circ} \mathrm{C}$ for the coupling products, respectively.

Measurement of Circular Dichroism Spectra. Circular dichroism spectra were measured in benzene in terms of $\left.\mathrm{Co}(\mathrm{II})(\mathrm{sal})_{2}(\mathrm{R})-\mathrm{CHXDA}\right)$ together with a few azo compounds in order to elucidate the interactions between them.

\section{RESULTS AND DISCUSSION}

\section{Decomposition Products of Azo Compound}<smiles>[R]C(C)(C#N)N=NC([R])(C)C#N</smiles>

The decomposition products of the four azo compounds in benzene at $82^{\circ} \mathrm{C}$ are shown in Table II. Compound $\mathbf{I}(\mathrm{R}=\mathrm{Me})$ gave only the coupling product, while compounds with a bulkier $\mathrm{R}$ gave less amounts of coupling prod- 
Thermal Decomposition of Several Azo Type Initiators

Table I. Characterization of products in the decomposition reaction

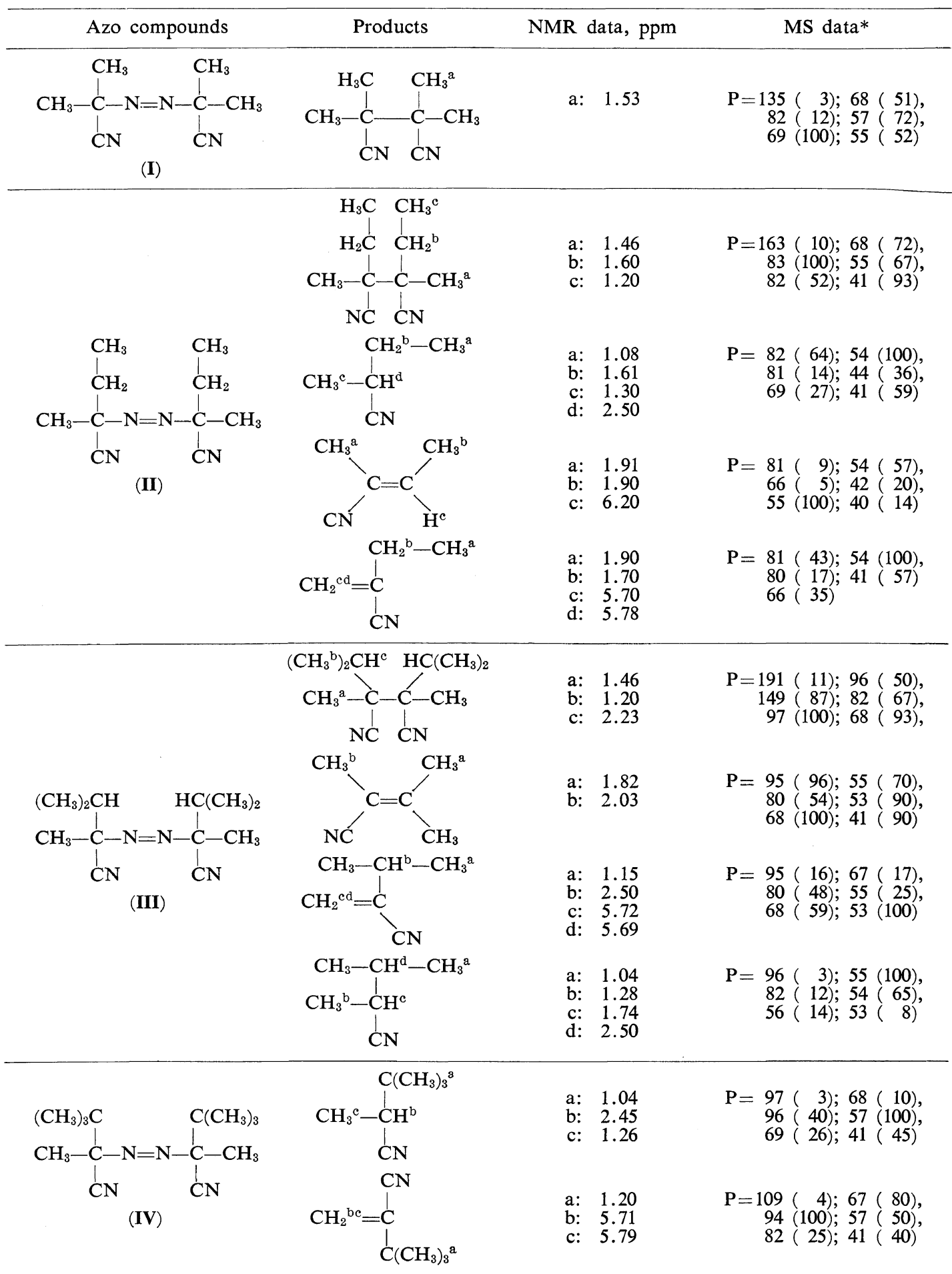

* The number in parentheses means relative intensity. 


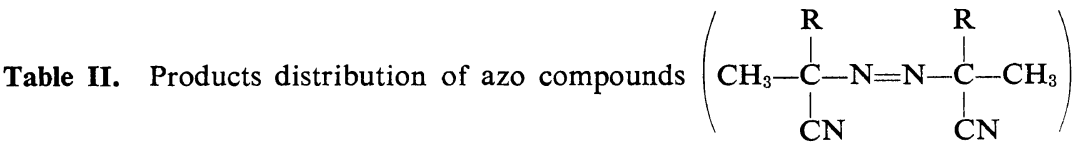
decomposed in the absence of the complex

\begin{tabular}{|c|c|c|c|c|c|}
\hline \multirow[b]{2}{*}{$\mathbf{R}$} & \multicolumn{5}{|c|}{ Products, $\%$} \\
\hline & $\begin{array}{c}\mathrm{R} \\
\mathrm{CH}_{3}-\stackrel{\mathrm{I}}{\mathrm{C}}-\mathrm{H} \\
\stackrel{\mathrm{C}}{\mathrm{C}}\end{array}$ & $\mathrm{CH}_{2}=\mathrm{C}_{\mathrm{CN}}^{\mathrm{R}}$ & Inner olefin & $\begin{array}{rl}\stackrel{\mathrm{R}}{\mathrm{l}} & \mathrm{R} \\
\mathrm{CH}_{3}-\underset{\mathrm{C}}{\mathrm{C}}- & \stackrel{!}{\mathrm{C}}-\mathrm{CH}_{3} \\
\mathrm{CN} & \stackrel{\mathrm{CN}}{\mathrm{C}}\end{array}$ & $\begin{array}{c}\text { Polymer } \\
+ \\
\text { unknown }\end{array}$ \\
\hline $\mathrm{CH}_{3}(\mathrm{I})$ & 0 & 0 & - & 100 & 0 \\
\hline $\mathrm{C}_{2} \mathrm{H}_{5}$ (II) & 6 & Trace & Trace & 86 & 8 \\
\hline iso $_{3} \mathrm{H}_{7}$ (III) & 13 & 6 & 1 & 72 & 8 \\
\hline$t-\mathrm{C}_{4} \mathrm{H}_{9}(\mathrm{IV})$ & 42 & 37 & 0 & 0 & 21 \\
\hline
\end{tabular}

Reaction conditions, [azo compound]; $0.1 M$ in benzene, $82^{\circ} \mathrm{C}$.

Table III. The effect of metal complexes on the mode of decomposition of

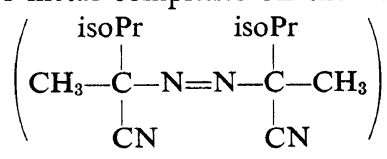

\begin{tabular}{|c|c|c|c|c|c|c|}
\hline \multirow[b]{2}{*}{ Complex } & \multicolumn{6}{|c|}{ Products, $\%$} \\
\hline & 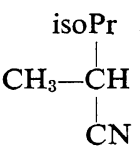 & ${ }_{\mathrm{CN}}^{\text {iso }}$ & $\underset{\mathrm{CH}_{3}}{\mathrm{CH}_{3}}$ & $\begin{array}{l}\mathrm{CH}_{3} \\
\mathrm{CN}\end{array}$ &  & $\begin{array}{c}\text { Polymer } \\
+ \\
\text { unknown }\end{array}$ \\
\hline - & 13 & 6 & & & 72 & 8 \\
\hline $\mathrm{Co}(\mathrm{II}) \mathrm{TPP}^{\mathrm{a}}$ & 36 & 0 & & & 8 & 12 \\
\hline $\mathrm{Co}(\mathrm{II})(\mathrm{sal})_{2}((\mathrm{R})-\mathrm{CHXDA})^{\mathrm{b}}$ & 33 & 0 & & & 37 & 0 \\
\hline $\mathrm{Ni}(\mathrm{II}) \mathrm{TPP} \mathrm{P}^{\mathrm{c}}$ & 38 & 0 & & & 22 & 10 \\
\hline $\mathrm{Cu}(\mathrm{II}) \mathrm{TPP}^{\mathrm{d}}$ & 15 & 4 & & & 65 & 14 \\
\hline $\mathrm{Mn}(\mathrm{II}) \mathrm{TPP} \bullet$ & 14 & 5 & & 1 & 70 & 10 \\
\hline
\end{tabular}

a [Azo compound], $0.05 M$; [Co(II)TPP], $1.5 \times 10^{-3} M$; b [azo compound], $0.1 M$; [Co(II)(sal $)_{2}((\mathrm{R})-$ CHXDA)], $5.3 \times 10^{-4} M$; c [azo compound], $0.05 M$; [Ni(II)TPP], $6.9 \times 10^{-4} M$; d [azo compound], $0.1 M$; [Cu(II)TPP], $5.3 \times 10^{-4} M ;$; [azo compound], $0.1 M ;$ [Mn(II)TPP], $4.7 \times 10^{-4} M$. Reaction conditions, at $82^{\circ} \mathrm{C}$ in benzene for 2 days.

ucts. No coupling product at all was detectable with compound IV which possesses the bulkiest substituent $(\mathrm{R}=t-\mathrm{Bu})$.

Thermal decomposition reactions of the azo compounds were carried out also in the presence of several metal complexes (Table III).

From Tables II and III, it can be seen that some of the metal complexes examined markedly change the distribution of the decomposition products. The presence of these metal complexes suppresses the formation of coupling product.
Figure 1 shows the effect of the concentration of complexes on the relative amount of coupling product.

The suppressing effect of the metal complexes upon the coupling reaction decreases in this order: $\quad \mathrm{Co}(\mathrm{II}) \mathrm{TPP} \sim \mathrm{Co}(\mathrm{II})(\mathrm{sal})_{2}((\mathrm{R})-\mathrm{CHXDA})>$ $\mathrm{Ni}(\mathrm{II}) \mathrm{TPP}>\mathrm{Cu}(\mathrm{II}) \mathrm{TPP} \sim \mathrm{Mn}(\mathrm{II}) \mathrm{TPP}$. The largest effect found in the cobalt complexes may be attributed to the divalent state which has a free radical character owing to seven electrons in $d$-orbitals. It is conceived that the primary 
radicals derived from the azo compound are stabilized more with the enhanced interaction with cobalt complexes. The coupling reaction of such stabilized radicals is suppressed, resulting in the predominant formation of noncoupling products.

It should be noted that some of the metal complexes examined, e.g., $\mathrm{Co}(\mathrm{II}) \mathrm{TPP}, \mathrm{Ni}(\mathrm{II}) \mathrm{TPP}$, and $\mathrm{Co}(\mathrm{II})(\mathrm{sal})_{2}((\mathrm{R})-\mathrm{CHXDA})$, have a tendency to form inner olefins $\left(\mathrm{C}=\mathrm{C}^{\prime}\right)$ rather than terminal olefins $\left(\mathrm{CH}_{2}=\mathrm{C}^{\prime}\right)$, the latter occupying the main part of olefins formed in the absence of these metal complexes. These results may suggest that the metal complexes also participate in the disproportionation reaction. A possible mechanism may be a hydrogen-transfer reaction with the aid of the metallic species.<smiles>CC(C)C(C)C#N</smiles>

(A)

<smiles>CC(C#N)C(C)C=[14C]C(Cl)Cl</smiles>

When $0.05 M$ of azo compounds was decomposed in the presence of $3.7 \times 10^{-4} \mathrm{M}$ of $\mathrm{Co}(\mathrm{II})$ $(\mathrm{sal})_{2}((\mathrm{R})-\mathrm{CHXDA})$, the amount of coupling product formed increases with temperature (Table IV). This fact may be explained in terms of the weakened ability of the cobalt salen complex to interact with free radicals at higher temperatures.

\section{Interaction of a Metal Complex with Azo Compounds}

It was reported previously that $2,2^{\prime}$-dimethyl2,2'-azodipropionitrile (compound I) was coordinated to a complex such as $\mathrm{AlEt}_{3}$ through
Table IV. Effect of temperature on the ratio of coupling product formed in the presence of $\mathrm{Co}(\mathrm{II})(\mathrm{sal})_{2}((\mathrm{R})-\mathrm{CHXDA})$ to that in absence of the metal complex

\begin{tabular}{|c|c|c|c|}
\hline \multirow{2}{*}{ Azo compound } & \multicolumn{3}{|c|}{ Relative amount } \\
\hline & $82^{\circ} \mathrm{C}$ & $92^{\circ} \mathrm{C}$ & $102^{\circ} \mathrm{C}$ \\
\hline $\mathrm{Ft} \quad \mathrm{Ft}$ & & & \\
\hline $\mathrm{CH}_{3}-\mathrm{C}-\mathrm{N}=\mathrm{N}-\mathrm{C}-\mathrm{CH}_{3}$ & 0.67 & 0.81 & 0.78 \\
\hline $\mathrm{CN}$ & & & \\
\hline isoPr & & & \\
\hline $\mathrm{CH}_{3}-\mathrm{C}-\mathrm{N}=\mathrm{N}-\mathrm{C}-\mathrm{CH}_{3}$ & 0.19 & 0.26 & 0.52 \\
\hline $\mathrm{CN}$ & & & \\
\hline
\end{tabular}

[azo compound], $0.05 \mathrm{M}$; [azo compound]/[complex $]=135$.

its CN group, as observed by means of IR spectrum. $^{6}$ In the present study, however, no distinct difference was observed in the IR spectra of azo compounds even in the presence of the cobalt complexes. On the other hand, the circular dichroism (CD) spectrum of $\mathrm{Co}$ (II) $(\mathrm{sal})_{2}((\mathrm{R})-\mathrm{CHXDA})$ in benzene changed greatly by the coexistence of any of the azonitriles listed in Table II. The most probable explanation is that the optically active cobalt complex will come close enough to the azonitrile molecule to interact with it.

\section{The Role of the Classical Solvent Cage}

On the basis of the distribution of the decomposition products from an unsymmetrical azo compound (V) (Table V), it should be possible to estimate qualitatively the extent of participation of the coupling reaction in "the classical solvent cage," because the symmetrical coupling products should not be formed in "the cage."

The mole ratio of unsymmetrical coupling product to the sum of symmetrical coupling products in the presence of $\mathrm{Co}(\mathrm{II})(\mathrm{sal})_{2}((\mathbf{R})$ CHXDA) were found to be approximately one to one, except for run 2.* If we assume that the metal complexes interact with radicals only in the region outside of "the classical solvent cage," the probability for the formation of the

* Some errors in the experimental technique might be associated with this run. 


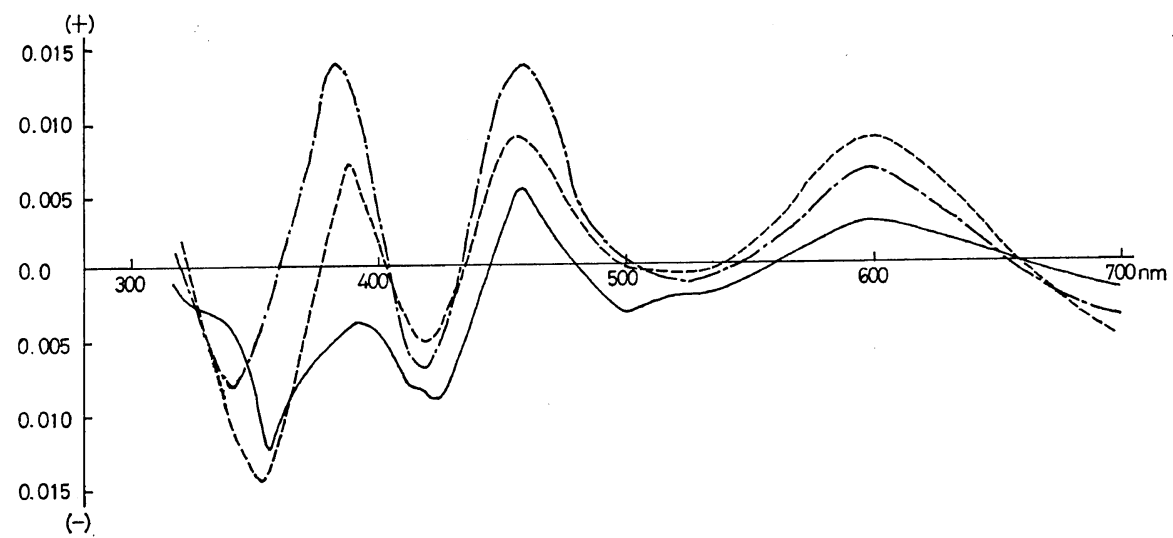

Figure 1. Circular dichroism spectrum of $\left.\mathrm{Co}(\mathrm{II})(\mathrm{sal})_{2}(\mathrm{R})-\mathrm{CHXDA}\right)$ in the presence or absence of azo compounds. Measured at $22^{\circ} \mathrm{C}$ in benzene: - $\mathrm{Co}(\mathrm{II})(\mathrm{sal})_{2}((\mathrm{R})-\mathrm{CHXDA})(1.78 \times$ $\left.10^{-4} M\right)$; - - -, $\mathrm{Co}(\mathrm{II})(\mathrm{sal})_{2}((\mathrm{R})$-CHXDA $)\left(1.78 \times 10^{-4} M\right)+$ azo compound $(\mathrm{I})\left(1.07 \times 10^{-1} M\right)$; ----, $\mathrm{Co}(\mathrm{II})(\mathrm{sal})_{2}((\mathrm{R})-\mathrm{CHXDA})\left(1.78 \times 10^{-4} M\right)+$ azo compound $(\mathrm{III})\left(6.2 \times 10^{-2} M\right)$.

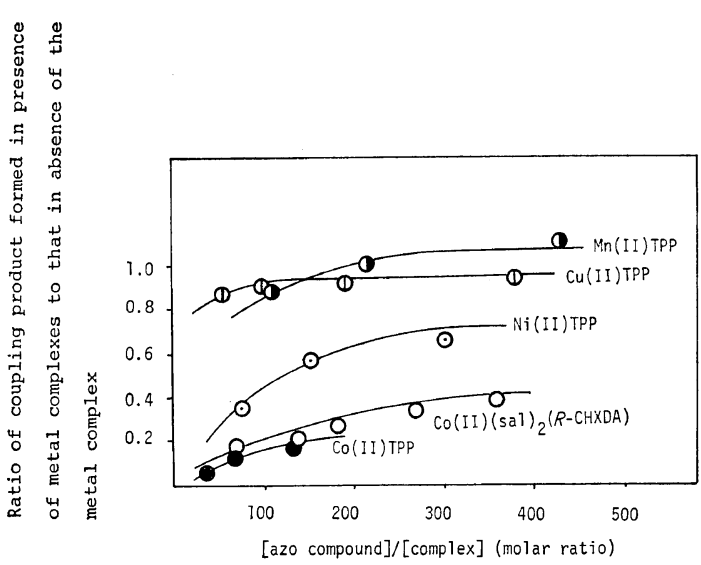

Figure 2. Effect of complexes on the amount of dimer formed: [azo compound],

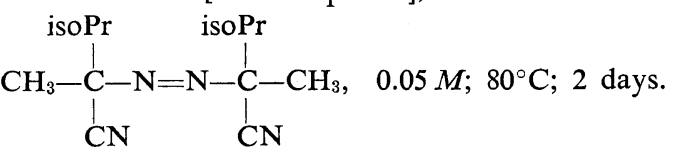

symmetrical coupling products should decrease with the increase of the concentration of the metal complexes in the reaction system, because coupling reactions were found to be supressed in the presence of the metal complexes as shown in Table III. Therefore, the mole ratio of symmetrical to unsymmetrical coupling products would have decreased with the increase in the concentration of the metal complex, contrarily to our observation (Table V). The results ob- tained in the present study can be interpreted by assuming that no participation of "the classical solvent cage" is operative in the present reaction system; that is to say, all of the radicals formed in the reaction system have equal chances in terms of chemical behaviors toward the metal complex. Judging from the CD spectra shown in Figure 1, we propose that azonitrile molecules are present under the interaction with the cobalt complex within a rather large and loose shell of solvent molecules.

The results shown in Figure 2 and Table II are also interpreted from the same point of view on the reaction mechanism.

Two possible structures may be considered as the intermediate responsible for the stabilization of radicals within the shell of solvent molecules.

$$
\begin{aligned}
& {\left[\begin{array}{c}
\mathrm{R}-\mathrm{N}=\mathrm{N}-\mathrm{R} \\
\mathrm{Co}
\end{array}\right] \longrightarrow} \\
& {\left[\begin{array}{c}
\mathrm{R} \cdot \mathrm{N}=\mathrm{N}-\mathrm{R} \\
\mathrm{Co}
\end{array}\right] \text { or }\left[\begin{array}{c}
\mathrm{R} \cdot \mathrm{N}_{2} \cdot \mathrm{R} \\
\text { Có }
\end{array}\right]}
\end{aligned}
$$

(C)

Although the present study cannot afford a decisive answer to the question about the two proposed formulas, it is more plausible to assume (B) as the structure of the intermediate in operation, because the relative amount of coupling products decreases in the presence of 


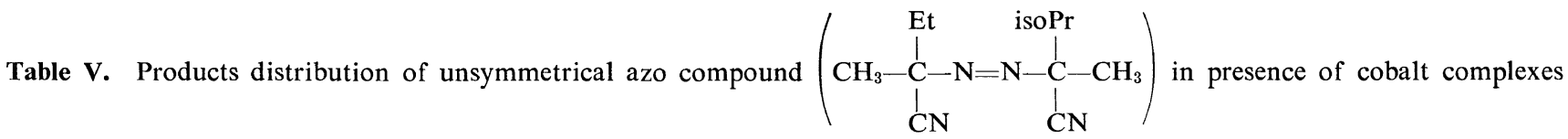

\begin{tabular}{|c|c|c|c|c|c|c|c|c|c|c|}
\hline \multirow[b]{2}{*}{ Run } & \multirow[b]{2}{*}{$\frac{[\text { Azo compound] }}{\left[\begin{array}{l}\text { [Complex] } \\
\text { molar ratio }\end{array}\right.}$} & \multicolumn{8}{|c|}{ Products, $\%_{0}^{\prime}$} & \multirow[b]{2}{*}{$\begin{array}{l}\text { Formation } \\
\text { ratio of } \\
(2) /(1)+(3)\end{array}$} \\
\hline & & $\begin{array}{l}\text { Et } \\
\mathrm{C}-\stackrel{\mathrm{C}}{\mathrm{l}} \\
\mathrm{CN}\end{array}$ & $\mathrm{C}=\underset{\mathrm{C}}{\mathrm{C}} \stackrel{\substack{\mid \\
\mathrm{CN}}}{\mid}$ & $\begin{array}{c}\text { isoPr } \\
\mathrm{C}-\stackrel{!}{\mathrm{C}} \\
\stackrel{\mathrm{C}}{\mathrm{C}}\end{array}$ & ${ }_{C^{\prime}}^{\mathrm{C}}$ & ${ }^{\mathrm{C}}$ & 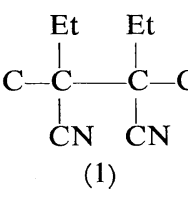 &  & 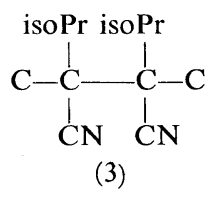 & \\
\hline 1 & - & 4 & 5 & 9 & 0 & & 22 & 44 & 16 & 1.16 \\
\hline 2 & $637^{\mathrm{a}}$ & 12 & 0 & 11 & 16 & & 26 & 25 & 11 & 0.68 \\
\hline 3 & $430^{a}$ & 12 & 0 & 12 & 17 & & 20 & 29 & 10 & 0.97 \\
\hline 4 & $295^{a}$ & 15 & 0 & 12 & 23 & & 19 & 26 & 5 & 1.08 \\
\hline 5 & $151^{\mathrm{a}}$ & 19 & 0 & 13 & 25 & & 17 & 22 & 4 & 1.05 \\
\hline 6 & $157^{\mathrm{b}}$ & 33 & 0 & 10 & 41 & & 10 & 6 & 0 & 0.60 \\
\hline
\end{tabular}

[azo compound], $0.1 M, 80^{\circ} \mathrm{C}$ in benzene for 2 days. a [Co(II)(sal) $\left.)_{2}((\mathrm{R})-\mathrm{CHXDA})\right]$; ${ }^{\mathrm{b}}[\mathrm{Co}(\mathrm{II}) \mathrm{TPP}]$. 
a metal complex. The metal complexes are considered to participate in the decomposition reaction before the formation of radicals within the solvent shell, because interactions between an azo compound and the complex, $\mathrm{Co}(\mathrm{II})(\mathrm{sal})_{2}-$ ((R)-CHXDA), were observed in CD spectra, and no change at all was observable in the distribution of the coupling products of an unsymmetrical azo compound in the absence or presence of the metal complex.

\section{CONCLUSION}

The present study has revealed that the mode of the decomposition reaction of a series of azo-type initiators depended strongly upon the bulkiness of substituents. The ratio of the coupling products to noncoupling ones decreases with an increase in bulkiness of the substituents. It was also found that some transition metal complexes, especially cobalt com- plexes, caused a prominent influence on the products distribution in the decomposition reaction. The effect of the metal complexes is explained in terms of the stabilization of radicals through the interaction with $d$-orbitals of the metal species.

\section{REFERENCES}

1. J. Thiele and K. Heuser, Ann., 290, 1 (1896); C. G. Overberger, M. T. O'Shaughnessy, and H. Shalit, J. Am. Chem. Soc., 71, 2661 (1949).

2. C. G. Overberger and M. B. Berenbaum, J. Am. Chem. Soc., 73, 2618 (1950).

3. J. E. Falk, "Porphyrins and Metalloporphyrins," Elsevier, Amsterdam, 1964.

4. P. Pothemund and A. R. Menotti, J. Am. Chem. Soc., 70, 1808 (1948).

5. H. Aoi, M. Ishimori, S. Yoshikawa, and T. Tsuruta, J. Organometal. Chem., 85, 241 (1975).

6. T. Hirano, T. Miki, and T. Tsuruta, Makromol. Chem., 104, 230 (1967). 